\title{
LA GUERRA CIVIL EN LA NOVELA ESPAÑOLA ACTUAL. ENTRE EL CONSENSO DE LA TRANSICIÓN Y EL CONSENSO NEOLIBERAL
}

\author{
David Becerra Mayor* \\ Université catholique de Louvain, Louvain-la-Neuve, Bélgica \\ david.becerra@uclouvain.be
}

\section{RESUMEN / ABSTRACT}

En los últimos años, un gran número de novelas sobre la Guerra Civil española han aparecido en el mercado literario. Se trata de un fenómeno extraño, sobre todo teniendo en cuenta que la sociedad que emergió después de la dictadura de Franco fue una sociedad desmemoriada, una sociedad que convirtió el pasado en un tabú. Sin embargo, a finales del siglo XX, la sociedad española empezó a organizarse para luchar contra el olvido, para recuperar el pasado. La Asociación por la Recuperación de la Memoria Histórica se funda en el año 2000 y, algunos años más tarde, en 2007, el gobierno de José Luis Rodríguez Zapatero (PSOE) aprueba la llamada Ley de la Memoria Histórica. En este contexto se produce la proliferación de novelas sobre la Guerra Civil. Este artículo intenta explicar este fenómeno literario y el modo en que la Guerra Civil se representa en estas novelas. El objetivo principal de este artículo es demostrar cómo estas novelas reproducen dos consensos: el consenso de la transición -amnesia, amnistía y equidistancia- $y$, por otro lado, el consenso neoliberal, que concibe que vivimos en tiempos post-políticos y en el denominado "fin de la historia".

Palabras clave: Guerra Civil, memoria histórica, novela española actual, consenso de la transición, consenso neoliberal.

Este trabajo se ha realizado con la ayuda del programa internacional de investigación "Move-in Louvain. Incoming post-doc Fellowship" de la Université catholique de Louvain. 
THE SPANISH CIVIL WAR IN THE CURRENT SPANISH NOVEL.

BETWEEN THE CONSENSUS OF THE TRANSITION AND THE NEOLIBERAL CONSENSUS

In the last few years a great number of novels dealing with the Spanish Civil War appeared in the literary market. It is a strange phenomenon, considering that the society that emerged after Franco's dictatorship was like a society without memory, a society that turned the past into a taboo. However, at the end of the twentieth century, the Spanish society begun to organize itself in order to fight against oblivion, to recover the past. The Association for the Recovery of Historical Memory was founded in 2000, and, a few years later, in 2007, during the administration of the president José Luis Rodriguez Zapatero (PSOE), the so-called Historical Memory Law was passed. This article tries to shed light on this literary phenomenon and how the Spanish Civil War is represented in these novels. The main objective of this article is to demonstrate how these novels reproduces two consensuses: the consensus of the Transition -based on amnesia, amnesty and equidistance-, and, on the other hand, the neoliberal consensus, that affirms we are living in post-political times and in the so-called "end of History".

KEYWORDS: Spanish Civil War, historical memory, current Spanish novel, consensus of Transition, neoliberal consensus.

Recibido: $26 / 03 / 2018$

Aceptado: 13/05/2018

En un cuento titulado "La desmemoria/ 4", Eduardo Galeano rememora el día en que visitó Chicago, una ciudad que observa llena de fábricas y llena de obreros. Cuenta el escritor uruguayo que al llegar al barrio de Haymarket les pidió a sus amigos que le mostraran "el lugar donde fueron ahorcados, en 1886, aquellos obreros que el mundo entero saluda cada primero de mayo" (Galeano 2013: 103):

-Ha de ser por aquí -me dicen. Pero nadie sabe.

Ninguna estatua se ha erigido en memoria de los mártires de Chicago en la ciudad de Chicago. Ni estatua, ni monolito, ni placa de bronce, ni nada,

continúa diciendo Galeano (103). Los mártires de Chicago habían sido borrados de la historia.

Sin embargo, en 1997, casi una década después de que Eduardo Galeano publicara su cuento en El libro de los abrazos (1989), la ciudad de Chicago se acordó de los huelguistas asesinados que reivindicaban la jornada laboral de ocho horas. Una placa rememora desde entonces la lucha por los derechos de los trabajadores. Parecía que al final se les hacía justicia a los mártires de Chicago. Pero un grafiti anarquista nos recuerda que a veces las políticas de 
la memoria, más que justicia, lo que llevan a cabo es una apropiación, por parte de los vencedores, de la memoria de los vencidos, para neutralizar su potencial político, al tiempo que son institucionalizados, normalizados. Frente a la apropiación de la memoria de los vencidos, la pintada de un modo harto elocuente decía: "First they took your life. Now they exploit your memory".

Traigo a colación este cuento de Galeano porque el silencio histórico que encuentra el escritor uruguayo en la plaza de Haymarket de Chicago bien puede parangonarse con la falta de homenaje y de reconocimiento a las víctimas del franquismo en la España que nació durante la transición de la dictadura a la democracia. Entre la muerte en cama del dictador (1975) y la promulgación de la Constitución (1978), se edificó el llamado "consenso de la Transición" sobre tres pilares que, en nombre de la reconciliación nacional, promovían la desmemoria y el desconocimiento del pasado: la amnesia, la amnistía y la equidistancia. El paso de la dictadura a la democracia se hizo a través de unos pactos de olvido y de silencio que instaban a la sociedad española a no mirar hacia el pasado, solamente a remar conjuntamente hacia un futuro de progreso y modernidad, con el propósito de poder lograr la ansiada "reconciliación nacional". Parecía que la reconciliación entre todos los españoles -superar la división de la sociedad entre vencidos y vencedores-solamente sería posible, en el contexto transicional, dándole la espalda al pasado. Como cuando Lot abandona la bíblica ciudad de Sodoma y la voz de Jehová le advierte que si mira hacia atrás se convertirá en estatua de sal, como finalmente le ocurrió a su mujer, la sociedad española de la transición nació con el miedo de Lot en el cuerpo, temiendo que si volvía su rostro hacia el pasado -concretamente hacia la Guerra Civil- se abrirían viejas heridas todavía sin cicatrizar. Se configura, en la transición española, lo que podríamos denominar "el deber de olvidar" frente al "deber de recordar" de Pierre Nora.

La Ley de Amnistía de 1977 -promulgada un año antes de que fuera aprobada la Constitución- legisló el olvido y la impunidad. Si bien la ley fue una conquista de la oposición antifranquista y con ella se logró la libertad de los presos políticos de la dictadura, en realidad sirvió para amnistiar a los torturadores y conceder impunidad a los victimarios, que nunca tuvieron que responder por sus crímenes ante la justicia. La Ley 46/1977 de Amnistía estipulaba la puesta en libertad de aquellos que hubieran realizado "actos de intencionalidad política, cualquiera que fuese su resultado, tipificados como delitos y faltas", pero a su vez esa misma ley incluía seis supuestos que, lejos de restablecer la justicia de las víctimas del franquismo, brindaba impunidad a sus victimarios: "en todo cosa están comprendidos en la amnistía (...) los 
delitos cometidos por funcionarios y agentes del orden público contra el ejercicio de los derechos y de las personas" (Apud Amorós 2014: 25). Como afirma la historiadora Carme Molinero:

Se podrá decir: ¡qué inocentes!, les estaban colando la impunidad de los responsables y agentes de la dictadura por crímenes cometidos a lo largo de tantos años. Es cierto (...) que aquella no era una prioridad de 1977 (...). Para los actores políticos de aquel momento la cuestión fundamental no era mirar al pasado; necesitaban todas las energías para construir el futuro, en el que tenían tantas esperanzas. Su gran objetivo era negar la legitimidad de la legislación franquista y construir el sistema democrático sobre bases consistentes (Molinero 2007: 219. Apud Amorós 2014: 25-26).

Como consecuencia de aquella ley, en España gozan todavía hoy de total impunidad los crímenes del franquismo. La Ley de Amnistía ha servido para bloquear, desde entonces hasta hoy, cualquier intento de llevar ante la justicia a los responsables de la violación de derechos humanos durante la dictadura franquista ${ }^{1}$.

El tercer pilar del consenso de la transición fue la noción de equidistancia, que impuso un relato que situaba en el mismo plano de responsabilidad a víctimas y verdugos ante las causas - y en cierta forma, ante las consecuenciasde la Guerra Civil española. Finalmente, y en contra del derecho internacional, se supeditó el "derecho a la paz" al derecho a conocer el pasado de acuerdo con los términos de "verdad, justicia y reparación". Es decir, verdad: qué pasó (fijar un relato, investigar las violaciones de los derechos humanos); justicia: posibilidad de que las víctimas se defiendan en un tribunal y combatir la impunidad; reparación: indemnización, restitución y rehabilitación $(C f r$. Escudero et al., 2013: 17-18). El deber de olvidar de la transición española tuvo -y sigue teniendo hoy- efectos en la sociedad española y en su forma de relacionarse con su pasado. Una sociedad no puede comprometerse con su pasado si no lo conoce; el desconocimiento conduce a la indiferencia. Y la sociedad española tiene enormes lagunas históricas acerca de su pasado

En 2010, la justicia argentina le exigió a España la extradición de varias personas implicadas en la represión franquista, siendo la "Querella argentina" la única que ha abierto causa contra los crímenes de la dictadura de Franco hasta el momento. Vid. Amorós (2014). 
más reciente, como así lo muestran las encuestas que magistralmente ha analizado el historiador Fernando Hernández Sánchez (2016)².

Las víctimas no recibieron reconocimiento ni homenaje, como los mártires de Haymarket de Galeano. Sin embargo, a pesar de que de la transición nació una sociedad desmemoriada, a finales del siglo XX y a principios del nuevo milenio la sociedad española empezó a organizarse para reivindicar el conocimiento de su pasado. La sociedad se enfrentó al silencio y al olvido institucionalizados, superando el miedo de convertirse en estatua de sal. Se fundó la Asociación para la Recuperación de la Memoria Histórica (ARMH) en el año 2000 y, unos años más tarde, en 2007, se aprobó la popularmente llamada Ley de Memoria Histórica durante el gobierno del presidente José Luis Rodríguez Zapatero (PSOE), a remolque de la movilización ciudadana pero a todas luces insuficiente ${ }^{3}$.

2 Sirva este ejemplo de los varios que estudia Hernández Sánchez: "Sondeos realizados al calor del septuagésimo aniversario del inicio de la Guerra Civil revelan que en 2006 persistía un alto índice de ignorancia de la historia del siglo XX español, ejemplificado en el desconocimiento, por casi un tercio (el 31,9\%) de los encuestados, de la identidad de algunos de sus más significados actores. El 74,4\% dijo saber lo que pasó el 18 de julio de 1936, pero un $23,1 \%$ aseguró no tener ni idea. El 43,1\% creía que debían "preservarse monumentos, estatuas o calles dedicadas a recordar el 18 de julio de 1936 o a sus protagonistas". El porcentaje subía hasta el 66,1\% entre los votantes del Partido Popular. El 30\% creía que la sublevación militar del 18 de julio de 1936 "estuvo justificada", mientras que la mitad opinó que no hubo ninguna justificación. El dato más positivo es que apenas a un 4,4\% de los encuestados el 18 de julio les inspiraba un sentimiento positivo, mientras para el 61\% era algo negativo" (Hernández Sánchez 2016: 6).

La ley recibió, como era esperable, críticas por parte de la derecha que, repitiendo el estribillo de la transición, acusaba a quienes reivindicaban una ley de la memoria histórica de querer abrir viejas heridas. Pero la ley también fue cuestionada por la izquierda y por los mismos movimientos de recuperación de la memoria histórica por considerarla a todas luces insuficiente. De entrada, resulta sintomático que el concepto "memoria histórica" no aparezca ni una sola vez en esa ley comúnmente llamada Ley de memoria histórica. Como explican los autores de Qué hacemos por la memoria histórica, "La Ley de memoria histórica nació atrapada entre dos almas. De un lado, la voluntad de reconocer los principios, derechos y valores de los que fueron reprimidos; de otro, por la intención de no romper el marco de la Transición legitimador del sistema consitucional (...), [lo que por ejemplo] se manifiesta en el rechazo del legislador a declarar nulas las sentencias y resoluciones dictadas en consejos de guerra y órganos judiciales franquistas guiados por razones políticas y en flagrante vulneración del derecho a un juicio justo. Si bien la Ley de memoria histórica califica de injustas estas sentencias y de ilegítimos los órganos que las dictaron, tales calificativos responden solo a un reproche moral y político, pero sin consencuencia jurídica alguna" (Escudero et al. 2013: 38-39). 
Es en este contexto político, social y cultural en el que se ha producido en España un fenómeno que merece sin duda un análisis detenido: la proliferación de novelas sobre la Guerra Civil española. En los últimos años ha habido en España un boom de la memoria, e incluso podemos afirmar que la Guerra Civil ha dejado de ser un tabú para convertirse en una auténtica moda literaria (Cfr. Becerra Mayor 2015). Como apunta Jaune Peris Blanes,

[1]o que singulariza a los recientes derroteros de los discursos y representaciones de la guerra es que han sido absorbidos, en buena parte, por una emergente industria cultural de la memoria. Por una parte, ello somete a buena parte de estos textos a las exigencias productivas de la industria cultural y mezcla, en muchos casos, los criterios artísticos, académicos o ideológicos con la necesidad de rentabilidad comercial privilegiando, por ejemplo, los componentes dramáticos y narrativos de la Historia sobre su análisis racional (Peris Blanes 2010: 3).

Luis Martín-Cabrera apunta, por su parte, lo siguiente:

La integración de la memoria en esta lógica de mercado transforma estas narrativas en mercancías que adquieren valor solo cuando son intercambiadas por otras narrativas en el mercado de las ideas. Además de disolver todas las formas de antagonismo político, la mercantilización de la memoria opera en conjunto con el olvido del pasado y la clausura de la historia (Martín-Cabrera 2016: 64).

Las novelas que sobre la Guerra Civil se escriben y publican en la actualidad podrían interpretarse como una clara ruptura con ese "deber de olvidar" de la transición del que hablábamos y como una forma de reconocimiento hacia las víctimas del pasado. Estas novelas, en definitiva, podrían definirse, a priori, como "novelas de la memoria histórica" que contarían, entre sus propósitos y objetivos, reivindicar la memoria frente al olvido y el silencio impuesto durante la transición. Estas novelas acaso funcionarían como la palaca que recuerda los mártires de Chicago. Pero, ¿ha sido la memoria mercantilizada $\mathrm{y}$, en consecuencia, neutralizada? Si así fuera, ¿será preciso pintar, también en nuestro caso, un grafiti que denunciara la apropiación y la neutralización de la memoria: "Primero os quitaron la vida; ahora explotan vuestra memoria"?

1.- Decía Walter Benjamin, en sus Tesis sobre la historia, concretamente en su tesis numero VI, que: 
Articular el pasado históricamente no significa reconocerlo "tal y como propiamente ha sido". Significa apoderarse de un recuerdo que relampaguea en el instante de un peligro. Al materialismo histórico le toca retener una imagen del pasado como la que imprevistamente se presenta al sujeto histórico en el instante mismo del peligro [...]. El don de encender la chispa de la esperanza solo es inherente al historiógrafo que esté convencido de que ni los muertos estarán seguros ante el enemigo si es que este vence. Y ese enemigo no ha cesado de vencer (Benjamin 2008: 307).

A partir de la noción de memoria que atraviesa las tesis de Walter Benjamin, como un instrumento político y revolucionario que debe convocar el pasado para desestabilizar el presente, tendríamos que definir una "novela de la memoria histórica" como aquella que fuera capaz de mostrar la continuidad que existe entre el pasado vencedor y el presente, que no es sino su heredero. El presente se define, a partir de Benjamin, como la amortización de un pasado que logró imponerse-vencer-sobre otros pasados posibles. Nuestro presente es la amortización del pasado de los vencedores de la Guerra Civil, la dictadura y de la transición. No hubo ruptura con el pasado en la transición, sino simplemente eso: una transición. Las huellas de la ruptura-los movimientos políticos y sociales de oposición al franquismo que fueron los que en verdad hicieron posible el paso de la dictadura a la democracia, modificando la correlación de fuerzas y obligando a las élites políticas y económicas de la dictadura a aceptar la democracia como forma de Estado- fueron borradas durante la transición, cuyo relato oficial sostiene que la democracia fue una concesión de las élites -el rey Juan Carlos I de Borbón y el presidente Adolfo Suárez-y no una conquista de los de abajo.

Si el relato se impuso y se fijó desde arriba es porque ellos ganaron la batalla del relato. En la correlación de fuerzas de la transición, la oposición tenía la fuerza suficiente para poner fin a la dictadura pero no para establecer una democracia que supusiera una auténtica ruptura con el régimen anterior. El régimen continuó por otros medios. Es preciso mostrar esa continuidad que existe entre pasado y presente para poder establecer por fin esa ruptura tan necesaria con el franquismo y construir una verdadera democracia que ponga fin a la impunidad. Una memoria en un sentido benjaminano, revolucionaria, entiende que en la historia sigue relampageando la posibilidad de un presente distinto, pero para ello es preciso contar/construir la historia desde otro lugar, el lugar de los vencidos. Cuando no es posible rendirle justicia a los vencidos, significa que el verdugo sigue vivo y no ha cesado de vencer. Los 
fantasmas del franquismo siguen habitando nuestro presente, y sus víctimas siguen enterradas en las cunetas, sin recibir homenaje alguno, mientras que los victimarios siguen gozando de impunidad.

La narrativa actual sobre la Guerra Civil, lejos de mostrar esa continuidad entre el pasado vecedor y el presente amortizado, refuerza la idea de que el pasado es, en efecto, algo pasado, lejano, casi mítico, que nada tiene que ver con nuestro presente. Dice Fredric Jameson en El posmodernismo o la lógica cultural del capitalismo avanzado que en la posmodernidad la novela histórica funciona como un espejo al que el lector acude para ver su rostro reflejado en el pasado. Pero en vez de devolverle su reflejo, del espejo sale un destello de luz, siempre cegador, que impide a quien se mira en el espejo reconocerse en su pasado. Concibe, entonces, su historia como algo ajeno, inerte, inmóvil. La novela le impide al lector experimentar la historia de un modo activo (Jameson, 1991: 52). El espejo, además, hechiza a quien se mira, como estas novelas hechizan al lector por medio de sugerentes aventuras de pasión y muerte, de vidas heroicas, de ideales y de un futuro todavía por escribir. Estas novelas, pues, opacan la continuidad pasado/presente.

La invisibilización de la línea que conecta el presente con el pasado es lo que convierte a estas novelas en estériles desde el punto de vista de la memoria histórica. No se trata simplemente de pensar que han sido incapaces de articular un discurso con potencial para desestabilizar el presente. No es una cuestión de incompetencia, más bien de reproducción ideológica. Eva Illouz ha elaborado una teoría del best seller donde, además de historizar el género, trata de explicar los motivos por los que unos libros, y no otros, se convierten en auténticos fenómenos de masas. Para Illouz, un libro cosecha un gran éxito de ventas cuando se define "por su capacidad de captar valores y actitudes que, o bien ya son dominantes y están ampliamente institucionalizados, o están suficientemente difundidos para que un medio cultural pueda presentarlos como corrientes" (Illouz 2014: 16). Son novelas que captan el sentido común. Hay novelas, en la opinión de Illouz, que resultan muy "apropiadas" para su sociedad y, en consecuencia, funcionan en el mercado literario. Dicen aquello que la sociedad quiere oír. Son normalmente novelas que plantean un problema compartido por el grueso de la sociedad y, además, tratan de resolverlo en el mismo texto. A la manera de los cuentos folclóricos, los best sellers ofrecen guías para resolver simbólicamente las contradicciones sociales. Tanto la cultura popular como los best sellers muestran "cómo deben hacerse las cosas" en un orden social difícil y caótico (Illouz 2014: 33 y ss). Estos libros, aparentemente de evasión, cumplen, pues, una función ideológica 
específica. Siguiendo a Juan Carlos Rodríguez, lo que funciona en el texto no es tanto la evasión como una invasión de la ideología dominante: los textos reproducen y legitiman una visión del mundo en que este se presenta a sí mismo como cerrado y perfecto; la ideología nos invade por medio de una literatura de corte evasiva (Rodríguez 2002: 258).

El éxito de las novelas sobre la Guerra Civil española en la actualidad responde a que el tema empezó a preocupar a la sociedad, sobre todo a partir de la fundación de la Asociación por la Recuperación de la Memoria Histórica. La memoria de las víctimas empezó a aparecer en prensa, a ocupar la primera plana de la actualidad (Escuedero et al. 2013: 27 y ss). Esa vuelta al pasado podría poner en peligro los cimientos del consenso de la transición, sus pactos de olvido y de silencio, su Ley de Amnistía, su relato equidistante. $Y$ entonces la literatura operó, en tanto que aparato privilegiado de reproducción ideológica (Cfr. Balilbar y Macherey 1975: 44), en la captación de esta problemática para resolverla simbólicamente, pero no políticamente, desplazando las contradicciones radicales a favor de otras asumibles por el sistema. En este sentido, las novelas sobre la Guerra Civil que se publican en la actualidad, lejos de cuestionar el consenso de la transición, más bien lo apuntalan -como vamos a ver a continuación.

2.- Un análisis detenido de estas novelas nos permite observar que en ellas se activan al menos tres mecanismos ideológicos que legitiman el consenso de la transición. El consenso de la transición construyó una imagen de la Guerra Civil basada en estas tres ideas: de nuevo, la teoría de la equidistancia; la descripción de la Guerra Civil española como una guerra fratricida y fruto de la locura colectiva; y la normalización de una secuencia cronológica encaminada a borrar la sustancialidad histórica de la República española, presentándola únicamente como mero antecedente o causa de la Guerra Civil.

En primer lugar, es preciso definir la equidistancia como la proyección de "la imagen de los dos bandos enfrentados, repetida con buenas o malas intenciones a lo largo de los años, [que] alude al odioso postulado de la simetría entre las dos caras de una moneda o entre las dos bordas -las dos bandas-de un barco" (Greppi 2008: 107). Pero, en efecto, y como sugería Carmen Negrín en las IX Jornadas sobre la cultura de la República, celebradas durante el mes de abril de 2011 en la Universidad Autónoma de Madrid y dirigidas por el profesor Julio Rodríguez Puértolas, "Bando: ¿dos bandos? Un gobierno no es un bando" (Negrín 2012: 124). La novela española actual, sin embargo, contribuye a reforzar la idea de que el gobierno legítimo republicano sea 
considerado un bando, situándolo en una posición de simetría con respecto a los golpistas franquistas. La teoría de la equidistancia está muy presente en la narrativa española actual y se activa, por ejemplo, en Soldados de Salamina de Javier Cercas (2001), cuando sitúa en posición simétrica la muerte de Antonio Machado y el frustrado fusilamiento del escritor y falangista Rafael Sánchez Mazas desde el principio mismo de la novela:

Un día de principios de febrero de 1999, el año del sesenta aniversario del final de la guerra civil, alguien del periódico sugirió la idea de escribir un artículo conmemorativo del final tristísimo del poeta Antonio Machado, que en enero de 1939, en compañía de su madre, de su hermano José y de otros cientos de miles de españoles despavoridos, empujado por el avance de las tropas franquistas huyó desde Barcelona hasta Collioure, al otro lado de la frontera francesa, donde murió poco después. El episodio era muy conocido, y pensé con razón que no habría periódico catalán (o no catalán) que por esas fechas no acabara evocándolo, así que ya me disponía a escribir el consabido artículo rutinario cuando me acordé de Sánchez Mazas y de que su frustrado fusilamiento había ocurrido más o menos al mismo tiempo que la muerte de Machado, solo que del lado español de la frontera. Imaginé entonces que la simetría y el contraste entre esos dos hechos terribles -casi un quiasmo de la historia- quizá no era casual y que, si conseguía contarlos sin pérdida en un mismo artículo, su extraño paralelismo acaso podía dotarlos de un significado inédito [...]. El resultado fue un artículo titulado "Un secreto esencial" (Cercas 2001: 23).

Obsérvese el modo en que Cercas utiliza, de buen seguro de forma intencionada, la palabra "simetría" para establecer un paralelismo entre la muerte de Antonio Machado y el fusilamiento fallido del poeta falangista.

La teoría de la equidistancia coloca en simétrica posición a las víctimas y a sus verdugos, como si a ambas partes del conflicto hubiera que atribuirle la misma responsabilidad. No resulta difícil localizar en las novelas que sobre la Guerra Civil se escriben en la actualidad sentencias del tipo "en esta guerra y posguerra se han cometido muchas atrocidades por ambos bandos. Repito: por ambos bandos", extraída de la novela Donde nadie te encuentre de Alicia Giménez Bartlett (2011: 96); o en Dime quién soy de Julia Navarro: "¿Asesinos? Sí, en este país hay y ha habido muchos asesinos, pero no solo los nacionales, no, también los otros han matado a muchos inocentes" (Navarro 2010: 418). También Javier Marías habla en Tu rostro mañana de 
que el terror era el "mismo en ambas zonas, en siniestra simetría demente" (Marías 2002: 175).

La simetría en la inculpación y la exigencia de responsabilidad por la tragedia desatada es un tema recurrente en la literatura sobre la Guerra Civil. El historiador Francisco Espinosa Maestre, en su ensayo El fenómeno revisionista o los fantasmas de la derecha, donde desmonta las teorías construidas por la historiografía revisionista actual, saca a colación el modo en que la teoría de la equidistancia es empleada por Lorenzo Silva, autor de Carta blanca (2004), cuando el novelista dice, en relación con la ocupación fascista de Badajoz, que su novela "refleja el heró́smo y la infamia de los dos bandos. Los republicanos fusilaron, por ejemplo, a jubilados; y la represión nacional fue inhumana; pero entre sus filas hubo quien se jugó el tipo”. Ante una proposición de este tipo, Espinosa Maestre no puede sino apuntar:

Ahora resulta que los republicanos fusilaron a jubilados y que los fascistas se jugaron el tipo [...]. Y ya como colofón, y tras decir que en el palacio de congresos que se ha construido en lo que fue la plaza de toros de Badajoz, convendría que "haya un recuerdo de lo que significó aquello", Silva el ecuánime repite: "También vi que en el baluarte de Trinidad hay un monumento a los héroes de la Legión. Esto está bien porque fue gente que se dejó el pellejo; pero cabría colocar otro monumento a los carabineros que lucharon por la República en la ciudad". Parece que no importa nada que unos se dejaran el pellejo defendiendo la democracia y otros el fascismo. Por lo visto el tiempo todo lo iguala. Por esta regla de tres Europa estaría cuajada de monumentos a los nazis que se dejaron el pellejo... (Espinosa Maestre 2005: 90).

Ante reconstrucciones del pasado de este tipo, es de rigor esgrimir que situar en el mismo plano de responsabilidad a un gobierno legítimo y a los golpistas que atentan contra su legalidad responde, como afirma Serge Salaün, a una insidiosa maniobra revisionista:

Desde hace algunos años se propaga una nueva manera de enfocar la literatura y la cultura de la guerra de España, alrededor del dogma de la "equidistancia". El punto de partida se sitúa a mediados de los años ochenta cuando, después de la Transición y asentada la democracia, se pretende enfocar la historia de la guerra hacia perspectivas menos partidarias, menos doctrinarias y, sobre todo, menos maniqueas. Como si el fantasma de la guerra o de la dictadura fuera ya inofensivo, 
como si la visión supuestamente primitiva y drástica entre "buenos" y "malos" necesitara matizarse o suavizarse, hacia unas posiciones más humanas de perdón, reconciliación u olvido de un pasado que se quiere superado (Salaün 2008: 304).

Más adelante señala Salaün que la teoría de la equidistancia no solamente produce y legitima "cierta reescritura sesgada de la Historia, o ciertas omisiones" (304) debido a que "la doctrina del "justo medio" encaja mal con la realidad social, ideológica y política" (305); pero además, advierte sobre la peligrosidad política que conllevan este tipo de lecturas (o de reescrituras) de la historia al señalar que "suele ser el terreno abonado para empresas ideológicas solapadas de rehabilitación de este pasado dictatorial, presentado como ominoso durante más de una década" (304).

Resulta innegable la existencia de una violencia desmesurada y descontrolada en la zona republicana - producida sobre todo durante los primeros meses de la contienda- que la literatura fascista se apresuró en calificar de "terror rojo". Y acaso es de rigor no mirar hacia otro lado. Pero para comprender en su completa dimensión histórica este episodio dramático de la guerra, tiene que entenderse, en primer lugar, que la violencia fue desencadenada por la violencia que se inició tras el golpe de Estado. Como apunta José Luis Ledesma, "el atronador y dramático contexto en el que las matanzas tuvieron lugar no disculpa, pero sin él nada resulta inteligible" (Ledesma 2010: 231). En segundo lugar, también es de rigor señalar que, si bien es incuestionable la veracidad de este episodio histórico perteneciente a la Guerra Civil española, también es cierto que la violencia registrada en la zona republicana fue inmediatamente atajada por las instituciones gubernamentales republicanas en un intento de enderezar el rumbo y recuperar el control de la situación. El papel que asume el Estado republicano frente a la violencia cometida en su zona, en su intento de limitar la violencia espontánea, constituye el rasgo distintivo que hace que medie un abismo entre el denominado "terror rojo" y el "terror blanco" producido en las zonas ocupadas por las tropas de Franco. De esta opinión es Paul Preston:

Naturalmente, las atrocidades no se limitaron a la zona rebelde. Especialmente a principios de la guerra, hubo oleadas de asesinatos de curas y sospechosos de ser simpatizantes fascistas [...]. Sin embargo, si hubo una diferencia en los asesinatos en las dos zonas, esta yace en el hecho de que las atrocidades republicanas solían ser obra de elementos incontrolables, en unos días en que se habían sublevado las fuerzas del orden (Preston 2000: 91-92). 
Del mismo modo, Herbert R. Southworth afirma:

Sabemos que los líderes de la República la violencia condenaron de sus partidarios, y en algunos casos lograron limitarla. También sabemos [...] que, al revés en el campo republicano, la matanza se convirtió en la España de Franco en un forma de vida durante toda la guerra y muchos años después [...]. Contra estas matanzas, ningún falangista levantó la voz de protesta, ni un requeté, ni un general franquista, ni un sacerdote, ningún abad mitrado, obispo, cardenal o nuncio se indignaron (Southworh 2008: 232-233).

En definitiva, y como afirma Ángel Viñas en su libro:

Si en la zona republicana el Estado apenas si existió de facto en los primeros meses de la guerra, aunque nunca se desplomó totalmente, una de las claves sobre las que se asentó el proceso de recuperación paulatina de su autoridad fue, con el ejército y la economía, el "orden público". Esto se reflejó en la voluntad de retirar la administración de la violencia a los micropoderes y grupos armados que la aplicaban a su aire [...]. La correspondencia entre la progresiva reconstrucción del Estado y el descenso de las atrocidades es, a mi entender, incuestionable por más que se manifestara con distinta velocidad (Viñas 2006: 183).

No es, pues, de recibo seguir sosteniendo una visión de la Guerra Civil española desde una perspectiva equidistante. Tratar de igualar y de situar en el mismo nivel de responsabilidad a quienes atacaron a un sistema legítimo y democrático y a quienes, por el contrario, sufrieron la agresión de un golpe militar fascista no puede sino tildarse de tergiversación -consciente o inconsciente- de la historia. En este sentido, hacemos nuestras las palabras de Alberto Reig Tapia:

Una violencia era de signo defensivo ante el asalto al poder legítimamente establecido y, la otra, era de carácter ofensivo empezando por poner en peligro uno de los principios esenciales de toda sociedad civilizada: la seguridad jurídica. Conviene, además, recordar que todo código penal admite eximentes en caso de legítima defensa y agravantes en caso de agresión indiscriminada. Se trata de una cuestión cualitativa fundamental en torno a la cual giran todas las demás, pero de la que no puede prescindirse (Reig Tapia 1990: 14-15). 
El relato de la Guerra Civil también se construyó como una "guerra fratricida". En este sentido, no es casualidad que la novela de Javier Cercas, Soldados de Salamina, se inicie con una digresión sobre la separación de los hermanos Machado tras el golpe de Estado. Soldados de Salamina empieza con la publicación de un artículo de su protagonista, Javier Cercas, homónimo del autor real, donde se especula con la posibilidad de que si Antonio Machado se hubiera encontrado en la zona nacionalista en vez de en la zona republicana, como le sucedió a su hermano Manuel, se hubiera identificado, como este, con la causa franquista:

Poco después de la muerte de Antonio, su hermano el poeta Manuel Machado, que vivía en Burgos, se enteró del hecho por la prensa extranjera. Manuel y Antonio no solo eran hermanos: eran íntimos. A Manuel la sublevación del 18 de julio le sorprendió en Burgos, zona rebelde; a Antonio, en Madrid, zona republicana. Es razonable suponer que, de haber estado en Madrid, Manuel hubiera sido fiel a la República; tal vez sea ocioso preguntarse qué hubiera ocurrido si Antonio llega a estar en Burgos (Cercas 2001: 25).

Como tampoco puede ser tomado como casual que el protagonista de $L a$ noche de los tiempos de Antonio Muñoz Molina (2009) se apellide Abel, un rasgo que define el carácter de la novela remitiendo de inmediato al lector al fratricidio bíblico con la clara intención de representar la Guerra Civil española como una lucha entre hermanos.

Otro ejemplo claro en este sentido se localiza en el modo en que se describe la Guerra Civil en la novela Donde nadie te encuentre de Alicia Giménez Bartlett (2011). La novela, cuya trama no nos interesa explicitar ahora, recurre al tópico del fratricidio en distintas fases de la narración. De este modo se dice que en España "se trata de odio, de venganza, de maldad, de represión. Y todo ello entre hipotéticos hermanos nacidos en el mismo país" (2011: 67). Y en otro lugar: "Es lamentable que en la guerra muriera tanta gente. España es un país fratricida" (116). Y más explícitamente se añade más adelante:

Esta guerra ha separado a las familias de manera brutal [...]. Mi madre era hija de militares y estaba educada en una manera de pensar muy ordenada. No era muy de derechas, pero creía en Dios, iba a misa..., ya te imaginas lo que quiero decir. Se enamoró de mi padre, que era profesor de latín en un instituto, y se casaron sin gran oposición de las familias. Todo les fue muy bien hasta que llegó la 
guerra. Entonces las cosas se liaron. Mi padre dijo que defendía la República hasta el fin y...

- ¿Se separaron?

- Sí (399).

La guerra separó y enfrentó a familias, sin duda; es inegable que existió ese componente fratricida que enfrentó, como muchos textos reflejan, a familias, hermanos, padres e hijos, e incluso vecinos, y, en consecuencia, es de rigor que el tema aparezca representado en las novelas que sobre el conflicto bélico se han escrito. No obstante, la Guerra Civil no puede reducirse a esa visión fratricida de la historia, donde se aniquila todo componente político y social en virtud de una lectura donde las categorías abstractas como el odio y la venganza, e incluso el miedo que conduce a los personajes a actuar en contra de sus seres más cercanos, desplazan las categorías objetivas e imposibilitan un acercamiento histórico al fenómeno en cuestión. Categorías como las señaladas -odio, miedo, venganza, etc.- deben reconocerse como síntomas del conflicto, pero no como elementos determinantes que lo originan. Confundir las causas con las consecuencias, lo determinante y lo determinado, puede provocar un falseamiento total o parcial de los hechos históricos. Frente a esta lectura de la Guerra Civil en términos fratricidas, que reduce todo conflicto a un enfrentamiento entre hermanos, no podemos sino hacer nuestras las palabras de Adolfo Sánchez Vázquez:

...tampoco se justifica la tendencia a confundir los colores, las voces y los pasos al presentar la guerra más bien "incivil" -así la calificó, apenas desatada, Unamuno- como una guerra entre hermanos, igualmente brutales o igualmente nobles, como si los agresores y los agredidos, los verdugos y las víctimas, fueran igualmente culpables o inocentes. Con ello se pretende ocultar que la sangrienta guerra civil le fue impuesta al pueblo español por el fascismo nacional y extranjero, y que aquel, al resistir la agresión en las condiciones más desventajosas, no hacía más que cumplir con lo que su dignidad exigía (Sánchez Vázquez 1995: 26).

En efecto, la descripción de la Guerra Civil española en términos fratricidas enmascara y oculta lo que en realidad fue la guerra: una agresión del fascismo contra un sistema de gobierno legítimo y democráticamente electo por el pueblo español en unas elecciones libres.

Por último, muchas novelas que se publican hoy sobre la Guerra Civil proponen una secuencia histórica que en absoluto es inocente, aunque tampoco 
es una invención de los novelistas, sino que está muy arraigada -de hecho, la mayor parte de los libros de historia de la España del siglo XX presentan esa misma secuencia cronológica. La secuencia establece una continudad entre la República y la Guerra Civil, cuando lo lógico sería vincular la Guerra Civil con el franqusimo, en tanto que la segunda fue consecuencia de la primera. Sin embargo, al tiempo que se desvincula el franquismo de la guerra, se pone el foco en la República que, de inmediato, queda reducida a mero antecedente histórico, a una causa de la guerra que de forma casi inexorable e inevitable ha de llegar. La República pierde su autonomía histórica, su sustancialidad, parece que no se pueda explicar en sí misma, con sus logros, sus reformas y sus contradicciones, sin que estas desemboquen de forma inevitable en la Guerra Civil. Como si esta fuera una consecuencia del caos y de la situación conflictiva de una Segunda República española que no supo consolidar su proyecto y, en consecuencia, dio lugar al estallido de la Guerra Civil. Pero la historia, sabemos, no fue exactamente así.

Muchas novelas legitiman esta secuencia histórica. Desde Historia de una maestra de Josefina Aldecoa (1990) hasta La enfermera de Brunete de Manuel Maristany (2006), pasando por La noche de los tiempos de Antonio Muñoz Molina (2009), Inés y la alegría de Almudena Grandes (2010) o Riña de gatos de Eduardo Mendoza (2010). El espectro ideológico es variado, como se observa, y la reconstrucción de esa visión teleológica de la República tiene algunos puntos en común, pero también algunas diferencias. Por ejemplo, la descripción de la República que proyecta La noche de los tiempos de Muñoz Molina difiere de otras al mostrar esta que el estallido de la Guerra Civil no encuentra su causa en la reacción antirreformista de los sectores más conservadores de la sociedad española, como así sucede, por ejemplo, en la novela de Josefina Aldecoa o en la de Almudena Grandes, sino que deriva del carácter potencialmente insurreccional de las “dos Españas" enfrentadas que se devoran entre ellas (Becerra Mayor 2015: 75-130). Ante este relato, es preciso apuntar, en primer lugar, que la reducción del periodo republicano a mero antecedente del conflicto bélico supone la aceptación del discurso que sostiene que la conflictividad social que tuvo lugar en la primera mitad de la década de los treinta en España fue el desencadenante de la Guerra Civil. Sin embargo, hay que considerar lo siguiente:

Todas las repúblicas europeas que surgieron en los años veinte y treinta, salvo la de Irlanda, y eso incluye a Alemania, Austria, Checoslovaquia, Hungría, Polonia, Portugal y Grecia, acabaron acosadas por fuerzas reaccionarias y derribadas por regímenes fascistas o autoritarios. Y 
en todos los casos, y no solo en España, la condición necesaria para la consolidación y estabilización de la democracia fue también que una amplia mayoría de la población aceptara, o al menos tolerara, esos nuevos regímenes que habían nacido de una forma tan rápida y sin apenas derramamiento de sangre (Casanova 2007: 36).

No existía, pues, una causa intrínsecamente española que hiciera tambalear los cimientos de la República, sino que su inestabilidad se integraba en una coyuntura histórica internacional en la cual las clases reaccionarias -articuladas políticamente en torno al fascismo-iban a cometer una agresión contra los jóvenes e inestables, y todavía en vías de consolidación, regímenes democráticos. La República española no fue una excepción. Se concluye con ello que la República no fue la causa de la Guerra Civil española; al contrario, su derrota -que se inicia el verano de 1936- fue un efecto de la agresión del fascismo nacional e internacional que se estaba empezando a armar y a organizar para derrumbar los sistemas democráticos europeos.

En segundo lugar, hay que apuntar que, a pesar de lo que dijeron sus ideólogos, el fascismo no se levantó contra el fantasma comunista que amenazaba el país con la organización de una revolución marxista. Porque en la República no existía la posibilidad de que se produjera una "revolución proletaria ni mucho menos un golpe armado. Se trataba, ni más ni menos, de la revolución democrática reemprendida en 1931 -fracasados los intentos anteriores-, contenida en 1934, que había recobrado toda su pujanza y contaba con posibilidades de desarrollo legal" (Tuñón de Lara, 1974, II: 524-525). La presunta amenaza de la Revolución no es posible seguir sosteniéndola como causa -o instrumento de legitimación- de la Guerra Civil española.

Por último, si bien es cierto que el periodo republicano estuvo marcado por una situación de conflicto social muy acentuado, representación del cual son las insurrecciones anarquistas de 1932 y 1933 o los acontecimientos del octubre de 1934 en Cataluña y Asturias, pero también la rebelión del general Sanjurjo en 1932, hay asimismo que apuntar, haciendo nuestras las conclusiones de Julián Casanova, que:

Nada de eso, sin embargo, conducía necesariamente a una guerra civil. Esta empezó porque una sublevación militar debilitó y socavó la capacidad del Estado y del Gobierno republicano para mantener el orden. El golpe de muerte de la República se lo dieron desde dentro, desde el propio seno de sus mecanismos de defensa, los grupos militares que rompieron el juramento de lealtad a ese régimen en 
julio de 1936. La división del ejército y de las fuerzas de seguridad impidió el triunfo de la rebelión, el logro de su principal objetivo: hacerse rápidamente con el poder. Pero al minar decisivamente la capacidad del Gobierno para mantener el orden, ese golpe de Estado dio paso a la violencia abierta, sin precedentes, de los grupos que lo apoyaron y de los que se oponían. En ese momento, y no en octubre de 1934 o en la primavera de 1936, comenzó la guerra civil (Casanova 2007: 184).

Considerar que la Guerra Civil española es consecuencia directa de los desórdenes producidos en el periodo republicano supone aceptar la tesis que sostiene que lo que fue un golpe militar fascista que atentó contra la legalidad democrática fue más bien un acto de legítima defensa ante los altercados sociales. Una reconstrucción teleológica de la República, escrita desde el final, donde los acontecimientos históricos funcionan como elementos emergentes de lo que sucederá en el futuro, como ocurre en parte de las novelas que hoy se escriben sobre la República/Guerra Civil, está muy cerca -en algunos casos la proximidad es total- de seguir reproduciendo las tesis y legitimando acaso, sin cuestionárselo, los motivos de quienes construyeron el mito de la cruzada de Franco (incluso desde posturas políticas supuestamente progresistas y aun de izquierdas). Resulta obligado, desde el rigor que impone la historia y la crítica literaria, señalar y analizar el modo en que la República se desdibuja como objeto histórico en estas novelas. Frente a estos discursos, se impone la reivindicación de su autonomía histórica, pues, de lo contrario, convertida en mero antecedente, la República pierde su inteligibilidad histórica, su legitimidad política y su sentido.

Lejos, pues, de producir una memoria capaz de desestabilizar el presente amortizado de la España postfranquista, buena parte de las novelas que hoy en día se escriben sobre la Guerra Civil española no hacen sino apuntalar el consenso de la Transición, mostrando el conflicto que tuvo lugar en España entre 1936 y 1939 como una guerra entre hermanos que derivió del caos permanente que se vivió en una inestable República y que, en consecuencia, a la hora de repartir reponsabilidades, aparece siempre señalada como antecedente de una guerra que puso fin a la que, hasta la hora, ha sido la mejor experiencia democrática que ha tenido España.

3.- Sin embargo, el consenso de la transición solamente explica una parte de este boom de la memoria. En ellas se reproduce también lo que podemos denominar el consenso neoliberal, que reproduce y legitima la idea de que 
vivimos en tiempos postpolíticos, donde la lucha de clases ha sido abolida y superada y que, situados en el "Fin de la Historia", no vivimos sino en el mejor de los mundos posibles. De esta forma inicia Jameson la introducción de El posmodernismo o la lógica cultural del capitalismo avanzado:

Estos últimos años se han caracterizado por un milenarismo invertido en el que las premoniciones del futuro, ya sean catastróficas o redentoras, han sido sustituidas por la convicción del final de esto o aquello (el fin de la ideología, del arte o de las clases sociales; la crisis del leninismo, la socialdemocracia o el Estado del bienestar, etc., etc.): tomados en conjunto, todos estos fenómenos pueden considerarse constitutivos de lo que cada vez con mayor frecuencia se llama posmodernismo (Jameson 1991: 9).

Fue el politólogo estadounidense de origen japonés Francis Fukuyama con su artículo titulado “The End of History?", publicado en julio de 1989 en National Interest, y después reformulado en el libro The End of History and the Last Man en 1992, a quien se le debe atribuir el éxito de un sintagma que exterioriza de forma harto transparente la ideología posmoderna del capitalismo avanzado. La tesis central del texto de Fukuyama defiende que la humanidad ha cruzado la línea de meta de su evolución histórica con la consolidación de la democracia liberal, sistema político que representa, a su parecer, el estadio último de la evolución humana y que simboliza la idea universal de libertad (Fukuyama 1989: 34). El Estado del "Fin de la Historia" no puede ser sino liberal, pues según las convicciones ideológicas de Fukuyama, las nociones universales de libertad y democracia son constitutivas al liberalismo y a su forma de gobierno (5). El "Fin de la Historia" supone, consiguientemente, para Fukuyama, la consolidación de la democracia liberal como única aspiración coherente capaz de gobernar las diversas culturas y regiones del mundo (Fukuyama 1992: xiii). Y, en su opinión, resulta difícil imaginar un mundo radicalmente mejor en valores que el que encarna el capitalismo avanzado, o un futuro que no sea esencialmente democrático ni capitalista (empleando estas dos categorías como si de sinónimos se tratara) (106). Posteriormente añade con convicción que ningún otro sistema puede representar una mejora del orden presente que el capitalismo avanzado (51).

La tesis central de Fukuyama del "Fin de la Historia", en tanto que punto final de la evolución de la humanidad, se articula a partir de la derrota de las alternativas al sistema capitalista liberal. La URSS estaba empezando su proceso de descomposición en el momento en que Fukuyama se encontraba 
redactando las páginas de su artículo -sin duda "el gran cambio que inspiró esta versión del fin de la historia fue, por supuesto, el colapso del comunismo" (Anderson 1992: 98). En este sentido, y como dice con claridad Perry Anderson, "el fin de la historia no equivale a haber alcanzado un sistema perfecto, sino la eliminación de alternativas mejores" (105). Como sostiene Perry Anderson en otro lugar, citando a Jameson, el triunfo universal del capital se debe a la pérdida de su antinomia:

El triunfo universal del capital significa algo más que una simple derrota de todas las fuerzas que antaño se le opusieron, aunque sea también eso. Su sentido más profundo reside en la cancelación de las alternativas políticas. La modernidad toca a su fin, como observa Jameson, cuando pierde todo antónimo. La posibilidad de otros órdenes sociales era un horizonte esencial de la modernidad. Una vez se desvanece esa posibilidad, surge algo así como la posmodernidad (Anderson 2000: 126).

Y escribe el propio Jameson:

...jamás en su historia ha disfrutado el capitalismo de más holgura y espacio de maniobras: todas las fuerzas amenazadoras que generó contra sí mismo en el pasado -movimientos laborales e insurgencias, partidos socialistas de masa, incluso los propios estados socialistashoy parecen completamente desorganizadas, si es que no se han neutralizado eficazmente, de alguna manera; por el momento, el capital global parece capaz de seguir su propia naturaleza e inclinaciones, sin las precauciones tradicionales (Jameson 2001: 339).

En efecto, el derrumbamiento de la Unión Soviética, como constatación del fracaso del denominado socialismo real, ofreció a Fukuyama y a la ideología liberal la convicción de que, sin una alternativa real que pusiera en duda las garantías del sistema capitalista, no podría existir ningún movimiento histórico capaz de desestabilizar el capitalismo y de cuestionar el discurso del "Fin de la Historia":

El colapso de la URSS y su extensión hacia Europa oriental es el fenómeno que imprime fuerza central al argumento de Fukuyama [...]. La convicción de que no hay una alternativa económica viable para el mercado libre surge más bien del fracaso del comunismo soviético [...]. Si se ha llegado al fin de la historia, es esencialmente porque finalizó la experiencia socialista. Gran parte de la atracción intuitiva 
que despierta el argumento de Fukuyama proviene, en efecto, de la sensación de que estamos presenciando una gigantesca conmoción histórica a todo lo ancho de lo que fue alguna vez el bloque soviético, conmoción que por primera vez en la historia no parece motivada por un nuevo principio, sino más bien moverse -como en un vasto sueño- hacia acontecimientos que se conocen incluso antes de que se produzcan (Anderson 1992: 131).

Pero el comunismo no fue únicamente derrotado con la caída del campo socialista y el fin de la Guerra Fría: el "Fin de la Historia" supone a su vez la aniquilación del proletariado -queremos decir: un proletariado con conciencia de clase y organizado políticamente-en el interior del propio bloque capitalista. A ello contribuyeron las políticas neoliberales que tras la crisis de 1973 se pusieron en práctica con el ascenso de la derecha parlamentaria, encabezada por Ronald Reagan y Margaret Thatcher, en Estados Unidos y en Gran Bretaña, respectivamente, en la década de los ochenta. En este sentido, David Harvey se atreve a establecer una conexión no casual entre la irrupción posmodernista y el ascenso al poder de la derecha neoliberal y la consiguiente deconstrucción de las instituciones tradicionales del movimiento obrero, como son los sindicatos y los partidos políticos (Harvey 1998: 369). De la siguiente forma lo expone Perry Anderson:

Durante los años ochenta, una derecha victoriosa pasó a la ofensiva. En el mundo anglosajón, los gobiernos de Reagan y Thatcher, tras aplastar al movimiento obrero, procedieron a reducir la regulación y la redistribución. La privatización del sector público, los recortes de gastos sociales y unos altos niveles de desempleo se difundieron desde Gran Bretaña al continente, creando unas nuevas pautas de desarrollo neoliberal que finalmente fueron puestas en práctica por los partidos de izquierda no menos que por los de la derecha (Anderson 2000: 124-125).

La destrucción del proletariado revolucionario, a partir del debilitamiento de sus instituciones, desmoviliza a la clase obrera, la sume en una desorganización sin precedentes hasta llegar al punto de que la Internacional Socialista, a finales de la década de los ochenta, llega a abandonar "en gran medida lo que fue la misión de la socialdemocracia occidental europea durante la posguerra, el Estado del bienestar basado en el pleno empleo y la prestación universal" (125). 
La literatura ha interiorizado el discurso hegemónico -y así lo reproduce y lo legitima en sus textos- y el resultado ha sido la producción de discursos literarios en los que toda forma de conflicto ha quedado eludida o invisibilizada. En la literatura actual, las contradicciones ideológicas de nuestra época se enuncian bajo la forma de solución imaginaria, es decir, las contradicciones radicales se desplazan sustituyéndolas por contradicciones imaginariamente conciliables por la ideología dominante (Balibar y Macherey 1975: 34). De este modo, la huella de lo político y lo social se borra del texto a favor de otros discursos que la ideología asume, y los conflictos que la novela expresa se resuelven a través de una lectura de corte intimista, psicologista o moral (Becerra Mayor 2013). En este contexto, la vuelta al pasado constituye una nueva exteriorización de la misma ideología: porque cuando los autores han asumido que vivimos en un mundo sin conflicto, no pueden sino preguntarse: ¿con qué material se construyen las novelas? Porque sin conflicto no es posible la novela, si aceptamos la definición de la misma que propuso Bajtin en su clásico ensayo Teoría y estética de la novela. Es en su capítulo central, titulado "Épica y novela (acerca de la metodología del análisis novelístico)" (Bajtin, 1989: 449-485), donde Bajtin nos describe la novela según su carácter imperfecto, abierto, su proyección de futuro y la presencia de un héroe problemático, en oposición al universo cerrado y perfecto que representa la epopeya clásica. La cuestión es que si nuestro presente -tal y como lo define la ideología dominante- es cerrado y perfecto, se sitúa en el "Fin de la Historia", ¿cómo es posible la novela? O en otras palabras: ¿acaso vivimos tiempos no aptos para la novela? Bien lo parece, según los postulados de la ideología dominante. Por ello, nuestros autores, que han asumido la lógica del capitalismo avanzado, se ven obligados a acudir a un tiempo histórico problemático, imperfecto y todavía abierto. Los años de la Guerra Civil española son, en este sentido, idóneos para su propósito. Nuestros novelistas necesitan echar una mirada al pasado, a un pasado convulso y conflictivo, para poder armar una trama novelesca.

La prueba de ello se localiza en las palabras que Almudena Grandes incluye en la "Nota de la autora" que, a modo de epílogo, cierra su Inés y la alegría (2010). Allí la novelista afirma escribir sobre los "momentos significativos de la resistencia antifranquista" con el convencimiento de que sin esos "casi cuarenta años de lucha ininterrumpida [...] nunca habría llegado a ser posible la España aburrida y democrática, desde la que yo puedo permitirme el lujo de evocarla" (Grandes 2010: 720-721). Resulta interesante comprobar de qué forma tan transparente se exterioriza el inconsciente ideológico (Rodríguez 
1991) en apenas unas líneas. En ellas, la autora de Inés y la alegría se coloca en una situación de privilegio respecto al pasado por medio del sintagma "lujo de evocarla" en relación con la definición que ofrece de su presente y de su "España, aburrida y democrática". Con la utilización de estos dos adjetivos -aburrida y democrática- Grandes se está situando de lleno en el núcleo de la ideología del capitalismo avanzado que concibe nuestro universo político y social como perfecto y cerrado, carente de conflicto. Una vez la autora ha interiorizado y asumido el carácter aconflictivo de nuestro presente, se puede permitir el lujo de no hablar de su tiempo histórico - un presente en el que no pasa nada- para mirar hacia un tiempo pasado donde todavía reside la acción, el conflicto, un futuro todavía por construir y, en definitiva, la posibilidad de escribir una novela.

Llegados a este punto es necesario traer a colación estas palabras de Etienne Balibar y Pierre Macherey: "El mandamiento primero de la ideología literaria es: "Hablaré de todas las formas de lucha de clases salvo de aquella que te determina inmediatamente""' (Balibar y Macherey 1975: 32). Y esto es de lo que nos está hablando el inconsciente ideológico de Almudena Grandes, no solo en estas líneas, sino en la totalidad de su novela; pero no solo a través de ella habla la ideología, sino también del grueso de novelistas de la Guerra Civil que se publican en nuestros días. Al evocar un pasado conflictivo, como es el caso del de la Guerra Civil española, se pone en funcionamiento el mecanismo ideológico que desplaza la posibilidad de concebir nuestro presente como asimismo conflictivo. El lector, al observar los conflictos del pasado que se describen en nuestra literatura sobre la Guerra Civil, podrá inferir - por oposición a lo narrado- que vive en un tiempo sin conflicto, pero no porque en su presente no exista el conflicto, sino porque permanece invisibilizado, oculto, por la propia ideología dominante y por uno de sus aparatos privilegiados de reproducción ideológica: la literatura. En síntesis, y en palabras del escritor y crítico Matías Escalera Cordero, se trata de lo que sigue:

Se nos tima porque se utiliza el pasado novelado como excusa para huir del "presente novelable"; porque se rehúye y se evita la realidad en la que de verdad vivimos y que de verdad nos afecta, porque nos quema -y acaba abrasándonos-; porque en ella -claro- con cada postura - con cada verdadero "acto literario"- nos comprometemos... Escribir sobre los asesinos y las víctimas del pasado, nos evita escribir sobre los asesinos y las víctimas de hoy (Escalera Cordero 2007: 10). 
Pero no es necesario emitir referencias paratextuales, como se ha hecho al sacar a colación el epílogo de Inés y la alegría de Grandes, para comprobar que, en efecto, la reconstrucción del pasado que se lleva a cabo en la novela española actual supone a su vez una invisibilización de los conflictos presentes. En un número importante de novelas, pasado y presente conviven por medio del recurso literario de la analepsis narrativa, donde la trama se inicia en el presente, siempre aburrido y democrático, que diría Grandes, y desde el cual se narran ciertos episodios del conflictivo y convulso pasado de la Guerra Civil. Este recurso estético funciona en estas novelas como un mecanismo que, de forma muy transparente, deja al descubierto la ideología y la complicidad con la que nos relacionamos con nuestro pasado. Las novelas que se sirven de este recurso literario repiten un patrón similar o prácticamente idéntico: un personaje ubicado en el presente, que puede ser un novelista, un periodista o simplemente el nieto de un represaliado, de pronto descubre, casi por azar, un episodio turbio del pasado, concretamente de la Guerra Civil española, y ante lo enigmático del descubrimiento se dispone a indagar sobre ello. A propósito de este aspecto Celia Fernández Prieto ha escrito:

La búsqueda desborda siempre el objetivo inicial porque abre detalles inesperados, sugiere otros enigmas, incita la curiosidad y a menudo acaba obsesionando al investigador. Toda indagación del pasado surge desde una angustia del presente y tiene algo de viaje iniciático, de aventura epistemológica y de prueba psicológica y moral. Más aún cuando lo que se busca tiene que ver con un pasado extraño y sombrío, aún habitado por fantasmas, por muertos sin enterrar (Fernández Prieto 2006: 50).

La vuelta al pasado deriva, en una parte importante de las novelas, de una causa fortuita y nunca buscada de forma racional o intencionada por los protagonistas de las novelas. No se acude al pasado con el propósito de reparar el presente, precisamente porque no se visibiliza la necesidad de mejorar nada ni de establecer una ruptura en el continuum histórico: el discurso del "Fin de la Historia" no deja resquicios para transformaciones de ningún tipo $\mathrm{y}$, además, su representación del mundo, perfecta y cerrada, aniquila toda posibilidad de dinamitar el presente. Del mismo modo, los personajes que vuelven los ojos al pasado, para descubrir algún misterio oculto en él, se encuentran en una posición social acomodada o, en todo caso, en un estado de frustración que en ningún caso se atribuye a las propias deficiencias de la sociedad capitalista, sino a su falta de virtud o talento (reproduciendo, 
de este modo, el ideologema liberal de que toda problemática se localiza en el interior del sujeto). De esto último es un ejemplo claro el personaje de Soldados de Salamina de Javier Cercas (2001): un novelista frustrado cuyo primer libro fue acogido con notoria indiferencia por parte del público y la crítica, encuentra en un episodio de la Guerra Civil la posibilidad de resarcirse como novelista. La Guerra Civil le proporciona al protagonista de Soldados de Salamina -como a tantos personajes/autores de novelas de esta temática- la posibilidad de ganar la batalla contra la página en blanco, de superar su crisis creativa y de reconciliarse con el oficio de escritor. Parecido es el caso del protagonista de Mala gente que camina de Benjamín Prado (2006), un impertinente profesor de secundaria y director de instituto -que desprecia tanto su cargo de burócrata como la mediocridad académica con la que convive en distintos congresos científicos en los que participa- a quien el pasado conflictivo de España, formalizado en una novela que encuentra por casualidad, le confiere la posibilidad de escapar de su gris y anodina realidad e inmiscuirse en un mundo todavía abierto; o el protagonista de Dime quién soy de Julia Navarro (2010), un periodista sin éxito que termina por reconciliarse con la investigación periodística gracias a la indagación que realiza sobre una mujer que participó plenamente en la Guerra Civil española. Son todos ellos personajes que sienten en un primer momento cierta indiferencia hacia la memoria y hacia el pasado histórico, pero terminan acudiendo a él, de forma más o menos apasionada, cuando descubren que la historia que tienen entre manos les puede aportar una trama atractiva en su proceso de creación literaria. La memoria no repara el presente, solamente sus frustraciones individuales.

La historia no importa tanto como la realización del sujeto como individualidad plena y autónoma. El conocimiento de la hisotria no ha de servir para desestabilizar nuestra lectura del pasado y, en consecuencia, desestabilizar también un presente que no es sino la amortización de aquel pasado vencedor. Fredric Jameson hablaba, en este sentido, de la liquidación de la historicidad que se produce en las narraciones sobre el pasado en el capitalismo avanzado o posmoderno; esto es, la historia desaparece como el elemento que dota de significado el presente, que se desustancializa. Por este motivo, la novela histórica de la posmodernidad es una novela sin historicidad o, lo que es lo mismo, deshistorizada. El capitalismo avanzado, como dice el chiste de Žižek (2004: 91), ofrece el café sin cafeína, la nata sin grasa o la cerveza sin alcohol; habría que añadir: y novelas históricas sin historicidad. 
La liquidación de la historicidad es el denominador común de las novelas que sobre la Guerra Civil se escriben y publican en la actualidad. Este proceso se lleva a cabo por medio de una reconstrucción de la historia en que las contradicciones radicales del momento histórico que retratan se desplazan a favor de una lectura donde lo individual y lo humano ocupan la centralidad del discurso en detrimento de lo político y lo social. El conflicto se interpreta, en la narrativa actual sobre la Guerra Civil, por medio de categorías asumibles por la ideología dominante. No hay elementos de clase o políticos que expliquen el conflicto, solamente cuestiones individuales o, de un modo más abstracto, pertenecientes al "espíritu humano".

La novela actual sobre la Guerra Civil tiende a aproximarse al objeto histórico desde una perspectiva neohumanista, esto es, ofreciendo una descripción del conflicto político por medio de la noción de accidentalidad, a partir de la cual se interpreta que por debajo del conflicto/accidente subyace siempre el espíritu humano que iguala a todos los hombres. La guerra será solamente un accidente que, en absoluto, dividirá la unidad esencial del espíritu humano. La política no tiene cabida en este discurso, queda desplazada. En este sentido, cabe señalar la novela de Juan Eslava Galán titulada La mula (2003), donde algunos de los episodios históricos que la novela retrata encaminan al lector a refrendar esta interpretación neohumanista de la historia. La novela, de entrada, desde sus paratextos, dice presentar una desmitificación de la Guerra Civil española, cuando lo que en realidad se pone en juego es una despolitización de la guerra por medio de un personaje inocente e ignorante, ingenuo y sin conciencia de clase ni de la realidad que le rodea, que participa en la guerra desde el bando golpista. No se muestra en la novela a un cabo falangista, sino simplemente a un hombre, a un buen hombre, incluso. Del mismo modo, los demás personajes que desfilan por la novela se definen en términos similares. No hay elementos políticos ni sociales que los definan ni que determinen su actitud, y de inmediato se comprueba que las convicciones políticas que ha llevado a cada uno a defender una causa u otra no son sino una cuestión meramente superficial (o accidental), y que por debajo de este accidente histórico llamado Guerra Civil hay solo hombres; hombres que, en tanto que hombres, son iguales entre sí. Este hecho se comprueba de forma nítida en el capítulo 14 de La mula. La escena es fundamental para comprender su propósito neohumanista, pues allí se narra el momento en que soldados de ambos "bandos", en su día de permiso, acuden al pueblo desarmados; mezclados los unos con los otros, se comportan con normalidad, conversando, abrazándose, forjando amistades con sus iguales/enemigos. 
Todos ellos parecen predestinados al entendimiento: los de un bando tienen papel pero carecen de tabaco mientras que a los del bando enemigo les sucede lo contrario; no tienen más remedio que entenderse, y se entienden. Cuando la guerra se detiene, lo humano brota libre y entonces, aparcadas las diferencias, todos los hombres se reconocen entre sí ${ }^{4}$.

El mismo mecanismo se pone en funcionamiento en la escena nuclear de Soldados de Salamina de Javier Cercas. La trama argumental de la novela gira alrededor del instante en el que un miliciano, misteriosamente, y tras mirar a los ojos a su enemigo, perdona la vida al falangista Rafael Sánchez Mazas, que logra escapar de un fusilamiento fallido. Como un neogarcilasismo, la identificación entre los combatientes en la guerra enfrentados, se produce por medio de la mirada, como si "De aquella vista pura y excelente / salen espiritus vivos y encendidos, / y siendo por mis ojos recibidos, me pasan hasta donde el mal se siente", como rezan los versos del soneto VIII de Garcilaso. Los ojos -la mirada - funcionan en Soldados de Salamina de idéntica forma en que funcionaba en el animismo de Garcilaso: como una reproducción de la lógica de la verdad desnuda que es capaz de descubrir que "los "hombres" son (por su sustancia espiritual) "iguales"; por su sustancia "apariencial/ social", distintos" (Rodríguez 1991: 52). El neohumanismo de Soldados de Salamina convierte la huella de lo político -la ideología que enfrenta a Sánchez Mazas y al miliciano- en sustancia apariencial, en accidente, que oculta la verdad desnuda, la sustancia espiritual, en que los dos hombres enfrentados, en tanto que hombres, no son sino iguales ${ }^{5}$.

Del mismo modo, y sin salir de Soldados de Salamina, es interesante tener en cuenta el modo en que se lleva a cabo la despolitización del falangista Sánchez Mazas, en la novela, por medio de su humanización. Como esgrime el filósofo esloveno Slavoj Žižek en su ensayo Primero como tragedia, después como farsa, el enemigo se caracteriza, según la ideología liberal, por ser alguien que no ha sido escuchado: en el acto de escucha se produce

4 Según cuenta Enzo Traverso en su ensayo 1914-1945. La guerre civil européenne, escenas como la que cuenta La mula, donde los enemigos confraternalizan, eran frecuentes en las guerras anteriores a la Primera Guerra Mundial, donde las fuerzas contingentes se reconocían como "adversarios legítimos". A partir de la Primera Guerra Mundial y el inicio de un nuevo tipo de guerra, la "guerra total", que ya no enfrenta "adversarios legítimos" sino pueblos y naciones enteras, y donde se borra la distinción entre civiles y soldados, la posibilidad de una escena de este tipo se reduce considerablemente (Traverso 2007: 89 y ss).

5 Este aspecto de Soldados de Salamina lo he desarrollado en otro lugar (Becerra, 2018). 
una subjetivización que devuelve al enemigo su categoría de humano. En este sentido, Soldados de Salamina de Javier Cercas ofrece al falangista la posibilidad de poder contar su historia y por lo tanto de humanizar al enemigo. Podríamos afirmar, siguiendo a Žižek,que Soldados de Salamina propone que "la manera adecuada de luchar contra la demonización del Otro es subjetivizarlo, escuchar su historia, entender cómo percibe la situación" (2011: 47). Rafael Sánchez Mazas, a partir de entonces, escuchado y humanizado, se desfascistiza en la novela de Cercas. En esta línea, Jordi Font apunta que en la novela de Javier Cercas "podemos distinguir una humanización del cofundador de Falange" (Font 2004: 176). Y añade seguidamente:

...a pesar de sus responsabilidades indudables [de Sánchez Mazas] en la confección de un programa de odio hacia la democracia y los movimientos emancipadores de la izquierda, uno de los legitimadores ideológicos de la sublevación militar del 18 de julio también tendría derecho a que fuera mostrado su rostro más humano (176).

Y concluye:

Lo que percibimos es que el libro de Javier Cercas ha favorecido el afianzamiento de unas pautas sociales [...] que, a la hora de ofrecer una visión de la guerra civil y el franquismo, se acercan a lo que, en otros países que han sufrido la opresión del fascismo, se conoce como revisionismo (177).

La subjetivización del enemigo o su descripción neohumanista de la Guerra Civil son algunas de la estrategias que se llevan a cabo, en estas novelas, para aplicar esa liquidación de la historicidad de la que hablaba Jameson, y que en nuestra opinión es producto del consenso neoliberal. En el fondo no se trata de otra cosa que de convertir la historia en lo que Walter Benjamin llamaba, en sus Tesis, el "burdel del historicismo". En el burdel del historicismo "el pasado [...] nos espera como una ramera dispuesta a decir lo que el visitante quiera oír" (Reyes Mate 2009: 250). Parece que la historia, tal y como se reconstruye en las novelas históricas del capitalismo avanzado, se encuentra esperando a los novelistas como una puta de burdel dispuesta a ser penetrada y hacer lo que el visitante le ordene. En esta reconstrucción del pasado, en efecto, el novelista se introduce en la historia como quien penetra a la prostituta del burdel, esto es, con la falsa ilusión de poseerla pero sin llegar nunca a llenar su vacío. De este modo lo expone el crítico inglés Terry Eagleton en su comentario a la tesis XVI de Walter Benjamin: 
La historia homogénea (la historia que ha expulsado las huellas de la ruptura y la revolución) se parece a la ramera tanto en su disponibilidad inmediata como en su estéril vacío [...]. [La ramera] es continuamente penetrada pero nunca violada, llenada sin cesar pero siempre vacía (Eagleton 1998: 79-80).

La Guerra Civil, convertida en la ramera del burdel del historicismo, es continuamente revisada y revisitada, pero permanece siempre vacía, ya que no logran -ni acaso pretenden- llenar de significado e historicidad el pasado retratado. En el burdel del historicismo, consiguientemente, el historiador -así como nuestros novelistas- volverá sobre el pasado tantas veces como desee, pero nunca logrará aprehender su sentido.

Estas novelas ofrecen lo que el visitante quiere oír, lo que la clase dominante necesita para neutralizar el potencial político y emancipador que tiene volver a hablar, después de un tiempo de silencio, sobre la Guerra Civil española. Narraciones estériles que no van a engendrar una nueva historia, sino que están construidas únicamente para satisfacer el placer del lector. No buscan desestabilizar su mirada ni la sociedad en la que se inserta. No buscan movilizar el pasado para movilizar también el presente.

Decía Walter Benjamin que la revolución es una forma de disparar contra los relojes. Detener el tiempo para volver a empezar de nuevo, establecer una ruptura en el continuum. Estas novelas, sin embargo, según el análisis que hemos hecho de ellas, más que disparar contra los relojes, lo que hacen es darles cuerda. Acaso por eso quizá convenga tomar, como los anarquistas de Chicago, un spray para pintar un grafiti sobre sus páginas que diga: Primero os quitaron la vida; ahora explotan vuestra memoria.

\section{BIBLIOGRAFÍA}

Aldecoa, Josefina. Historia de una maestra. Barcelona: Anagrama, 1990.

Amorós, Marios. Argentina contra Franco. El gran desafio a la impunidad de la dictadura. Madrid: Akal, 2014.

Anderson, Perry. Los fines de la historia. Barcelona: Anagrama, 1992. Los orígenes de la posmodernidad. Barcelona: Anagrama, 2000.

Balibar, Etienne y Pierre Macherey. "Sobre la literatura como forma ideológica". en Louis Althusser et al., Para una crítica del fetichismo literario. Madrid: Akal, 1975. 23-46. 
Bajtin, Mijail. “Épica y novela (acerca de la metodología del análisis novelístico)”. Teoría y estética de la novela. Madrid: Taurus, 1989, pp. 449-485.

Becerra Mayor, David. La novela de la no-ideología. Madrid: Tierradenadie, 2013.

La Guerra Civil como moda literaria. Madrid: Clave Intelectual, 2015.

"La actualización del animismo en Soldados de Salamina y La lengua de las mariposas". En Natalie Noyaret (ed.), L'expression du silencedans le récit de fiction espagnol contemporain. Binge: Éditions Orbius Tertius, 2018. 279-295

Benjamin, Walter, "Sobre el concepto de Historia". Obras (libro I/vol. 2). Madrid: Abada, 2008.

Casanova, Julián. República y guerra civil. Barcelona: Crítica, 2007.

Cercas, Javier. Soldados de Salamina. Barcelona: Tusquets, 2001.

Eagleton, Terry. Walter Benjamin o hacia una crítica revolucionaria. Madrid: Cátedra, 1998.

Escalera Cordero, Matías. "El vacío abisal de una literatura sin realidad presente (ni pasada)". La (re)conquista de la realidad. Madrid: Tierradenadie, 2007.

Escudero, Rafael; Patricia Campelo; Carmen Pérez González y Emilio Silva. Qué hacemos por la memoria histórica. Madrid: Akal, 2013.

Eslava Galán, Juan. La mula. Barcelona: Planeta, 2003.

Espinosa Maestre, Francisco. El fenómeno revisionista o los fantasmas de la derecha española. Badajoz: Del Oeste, 2005.

Fernández Prieto, Celia. "Formas de representación de la guerra civil en la novela contemporánea española (1990-2005)". Guerra y literatura. XIII Simposio Internacional sobre narrativa hispánica contemporánea. Puerto de Santa María: Fundación Luis Goytisolo, 2006. 41-56.

Font, Jordi. “¿Está (de nuevo) la historia en pañales? Consideraciones a propósito de una lectura crítica de Soldados de Salamina". Historia presente 3 (2004): 169-184.

Fukuyama, Francis. “¿The End of History?”, National Interest 16 (1989): 3-16.

The End of History and the Last Man, New York, The Free Press, 1992.

Galeano, Eduardo. El libro de los abarzos. Madrid: Siglo XXI, 2013.

Giménez Bartlett, Alicia. Donde nadie te encuentre. Barcelona: Destino, 2011.

Grandes, Almundena. Inés y la alegría. Barcelona: Tusquets, 2010.

Greppi, Andrea. "Los límites de la memoria y las limitaciones de la Ley. Antifascismo y equidistancia". En José Antonio Martín Pallín y Rafael Escudero Alday, Derecho y memoria histórica. Madrid: Trotta 2008. 105-125.

Harvey, David. La condición de la posmodernidad. Investigación sobre los orígenes del cambio cultural. Buenos Aires: Amorrortu, 1998.

Hernández Sánchez, Fernando. “¿Fue Franco un mamífero?”. Pasos a la izquierda 4 (2016): 1-17. Disponible en internet: http://pasosalaizquierda.com/?p=1118 Consultado el 19 de marzo de 2018.

Illouz, Eva. Erotismo de autoayuda. Cincuenta sombras de Grey y el nuevo orden romántico. Madrid: Clave Intelectual, 2014.

Jameson, Fredric. El posmodernismo o la lógica cultural del capitalismo avanzado. Barcelona: Paidós, 1991. 
Teoria de la postmodernidad. Madrid: Trotta, 2001.

Ledesma, José Luis, "Una retaguardia al rojo. Las violencias en la zona republicana". Francisco Espinosa Maestre (ed.), Violencia roja y azul. España, 1936-1950. Barcelona: Crítica 2010. 147-247.

Marías, Javier. Tu rostro mañana 1. Fiebra y lanza. Madrid: Nuevas ediciones de bolsillo, 2008 [2002].

Maristany, Manuel. La enfermera de Brunete. Barcelona: Vedrà, 2006.

Martín-Cabrera, Luis. Justicia radical. Una interpretación psicoanalitica de las postdictaduras en España y el Cono Sur. Barcelona: Anthropos, 2016.

Mendoza, Eduardo. Riña de gatos. Barcelona: Planeta, 2010.

Molinero, Carme. "La política de la reconciliación nacional. Su contenido durante el franquismo, su lectura en la Transición", Ayer 66 (2007): 201-225.

Muñoz Molina, Antonio. La noche de los tiempos. Barcelona: Seix Barral, 2009.

Navarro, Julia. Dime quién soy. Barcelona: Plaza \& Janés, 2010

Negrín, Carmen. “La memoria revisitada”. En Julio Rodríguez Puértolas (coord.), La República y la cultura. Alicante: Biblioteca Virtual Miguel de Cervantes, 2012. 114-125.

Peris Blanes, Jaume. "Últimas noticias de la guerra. Procesos de novelización en las nuevas narrativas históricas sobre la Guerra Civil”. Espéculo. Revista de estudios literarios 4 (2010): 1-15.

Prado, Benjamín. Mala gente que camina. Mala gente que camina. Madrid: Alfaguara, 2006.

Preston, Paul. La Guerra Civil española. Madrid: Debolsillo, 2000.

Reig Tapia, Alberto. Violencia y terror. Madrid: Akal, 1990.

Reyes Mate, Manuel. Medianoche en la Historia. Comentarios a las tesis de Walter Benjamin "Sobre el concepto de Historia". Madrid: Trotta, 2009.

Rodríguez, Juan Carlos. Teoría e historia de la producción ideológica. Madrid: Akal, 1991. De qué hablamos cuando hablamos de literatura. Granada: Comares, 2002.

Salaün, Serge. "Romances y romanceros de la guerra”. En Manuel Aznar Soler et al. (eds.), València, Capital cultural de la República (1936-1937). Congrès Internacional. Universitat de València, 2008, pp. 293-318.

Silva, Lorenzo. Carta Blanca. Madrid: Espasa Calpe, 2004.

Southworth, Herbert R. El mito de la cruzada de Franco. Madrid: Debolsillo, 2008.

Sánchez Vázquez, Adolfo. "Entre la memoria y el olvido". En Manuel Aznar Soler (ed.), El exilio literario español de 1939. Barcelona: Gexel 1995. 23-30.

Traverso, Enzo. 1914-1945. La guerre civile européenne. París: Hachette, 2007.

Tuñón de Lara, Manuel. La España del siglo XX. Barcelona: Laia, 1974, 3 vols.

Viñas, Ángel. La soledad de la República. Barcelona: Crítica, 2006.

Žižek, Slavoj. Repetir Lenin. Madrid: Akal, 2004.

Primero como tragedia, después como farsa. Madrid: Akal, 2011. 